\title{
Cost Efficient Design of Mechanically Stabilized Earth Walls Using Adaptive Dimensional Search Algorithm
}

\author{
Saeid KAZEMZADEH AZAD ${ }^{1}$ \\ Ebru AKIŞ ${ }^{2}$
}

\begin{abstract}
Mechanically stabilized earth walls are among the most commonly used soil-retaining structural systems in the construction industry. This study addresses the optimum design problem of mechanically stabilized earth walls using a recently developed metaheuristic optimization algorithm, namely adaptive dimensional search. For a cost efficient design, different types of steel reinforcement as well as reinforced backfill soil are treated as discrete design variables. The performance of the adaptive dimensional search algorithm is investigated through cost optimization instances of mechanically stabilized earth walls under realistic design criteria specified by standard design codes. The numerical results demonstrate the efficiency and robustness of the adaptive dimensional search algorithm in minimum cost design of mechanically stabilized earth walls and further highlight the usefulness of design optimization in engineering practice.
\end{abstract}

Keywords: Mechanically stabilized earth walls, optimum design, adaptive dimensional search, cost optimization, discrete variables, metaheuristics.

\section{INTRODUCTION}

Civil engineering projects usually require construction of soil-retaining structural systems. In general, these structures can be classified into two main groups, namely externally and internally stabilized systems. In-situ walls and gravity walls are typical instances of externally stabilized walls while reinforced soils as well as in-situ reinforcements can be categorized as internally stabilized soil-retaining systems which have been utilized since 1960 [1]. Basically, the rationale behind the use of internally stabilized systems is to enhance the tensile behavior of soil which is obviously negligible compared to its high load bearing capacity under compression. For instance, mechanically stabilized earth (MSE) walls are among the most popular internally stabilized soil-retaining systems which are constructed

\section{Note:}

- This paper has been received on January 7, 2019 and accepted for publication by the Editorial Board on April 22, 2019.

- Discussions on this paper will be accepted by September 30, 2020.

- https://dx.doi.org/10.18400/tekderg.509468

1 Department of Civil Engineering, Atilim University, Ankara, Turkey - saeid.azad@atilim.edu.tr https://orcid.org/0000-0001-9309-607X

2 Department of Civil Engineering, Atilim University, Ankara, Turkey - ebru.akis@atilim.edu.tr https://orcid.org/0000-0001-8417-2405 
through reinforcement of soil by placement of reinforcing members such as metallic strips, geotextiles, or geogrids.

Generally, the basic components of MSE wall systems can be listed as reinforcements, backfill soil, facing elements and connection parts [2, 3]. These soil-retaining structural systems are mainly low-priced compared to the conventional reinforced concrete retaining structures especially under poor foundation conditions. Although the cost of MSE walls may vary as a function of several independent parameters, it mainly depends on the cost of its principal components i.e. facing system, backfill material, placement, reinforcing material, etc. According to Ref. [2], typical relative costs of main components of MSE walls are outlined in Figure 1. Since decision making on the type of reinforcing material as well as backfill soil has a significant effect on the final cost of MSE walls, these design parameters are investigated in the present study using an optimization based approach.

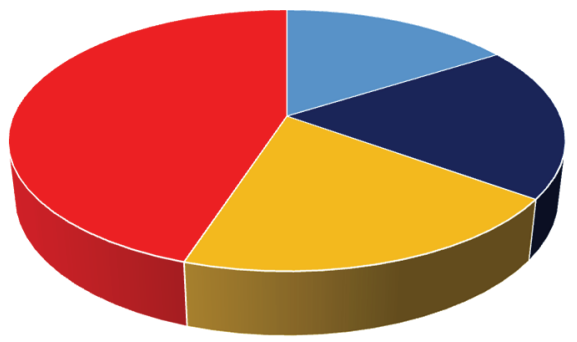

\footnotetext{
- Erection of panels and contractor's profit ( $20 \%$ to $30 \%$ of total cost)

- Facing system (20\% to $40 \%$ of total cost)

- Reinforcing materials (15\% to $30 \%$ of total cost)

- Reinforced wall fill including placement (30\% to $60 \%$ of total cost)
}

Figure 1 - Typical relative costs of main components of MSE Walls

One of the challenges in engineering design optimization is to develop efficient design optimization tools that can be used by designers to achieve cost-effective yet feasible final designs. Similarly, for optimum design of MSE walls, it is fruitful to adopt a suitable optimization method capable of handling the design variables as well as problem constraints [4-5]. Stochastic optimization techniques or the so called metaheuristics have found plenty of engineering design applications in the past decades [6-12]. The predominant characteristics of metaheuristics can be outlined as their independency on gradient information, capability of handling both discrete and continuous solution variables, and global search features to locate the optimum or near optimum solutions for challenging engineering design problems. These advantageous characteristics of stochastic search techniques make it possible to avoid cumbersome formulations of traditional structural optimization approaches, namely mathematical programming [13] and optimality criteria methods [14]. The state-of-the-art reviews of metaheuristic algorithms and their practical applications in engineering design can be found in Refs. $[15,16]$. 
Adaptive dimensional search (ADS) algorithm is a recently developed metaheuristic algorithm for minimum weight design of truss structures [17]. This population based optimization technique is working based on an evolutionary approach where at each iteration, after generation and evaluation of candidate designs, the best design found is used to generate a new population of candidate designs. In this algorithm, in order to adjust the explorative and exploitative features of the technique, the search dimensionality ratio is adaptively updated during the optimization iterations. Regarding the promising performance of the ADS demonstrated in Ref. [17] in the present study the algorithm is revised for minimum cost design of MSE walls under realistic design constraints. For a cost efficient design, different types of steel reinforcement as well as reinforced backfill soil are considered as discrete design variables. The performance of the ADS is investigated through different cost optimization instances of MSE walls under realistic design criteria. The obtained numerical results clearly indicate the usefulness of the ADS algorithm in minimum cost design of MSE walls.

An outline of this paper is as follows. The second section provides the design procedure of MSE walls under standard code considerations. The mathematical formulation of the tackled optimization problem is stated in the third section. In the fourth section the employed metaheuristic optimization technique is described in detail. The numerical examples of MSE walls are investigated in the fifth section. A summary of the present study as well as some concluding remarks are provided in the last section.

\section{DESIGN OF MECHANICALLY STABILIZED EARTH WALLS}

This section outlines the main steps for design of MSE walls as recommended in Refs. [2-3] and AASHTO (2010) [18] specifications. Generally, in order to design the MSE walls, two main stability analyses, namely external and internal stability evaluations are to be performed. The external stability analyses include the checks against sliding on the base, overturning about the toe, bearing capacity of the foundation soil, settlements of the structure, and overall stability failure. In addition to external stability checks commonly used in design of retaining walls, internal stability analyses, including the check against rupture and pullout of the reinforcements within the reinforced backfill zone, must be accomplished as well.

\subsection{External Stability Analyses}

In order to evaluate the external stability of MSE walls, sliding, limiting eccentricity (overturning), bearing capacity, and settlement checks are carried out according to AASHTO (2010) [18] design specifications. With respect to the acting forces on the MSE walls (Figures 2 and 3) the nominal and factored resisting and sliding forces are determined along the base of the wall in order to assess the MSE wall for sliding.

Here, the vertical traffic load or live load surcharge is not included in the external forces due to the stabilizing effect. According to Refs. $[1,2,18]$ the earth pressure from retained backfill $F_{1}$ and live load surcharge $F_{2}$ for MSE wall with level backfill and traffic load (Figure 2), are determined using Eqs. (1-2). Furthermore, the earth pressure from retained backfill $F_{T}$ for MSE wall with sloping backfill (Figure 3) is calculated through Eq. (3) as follows. 


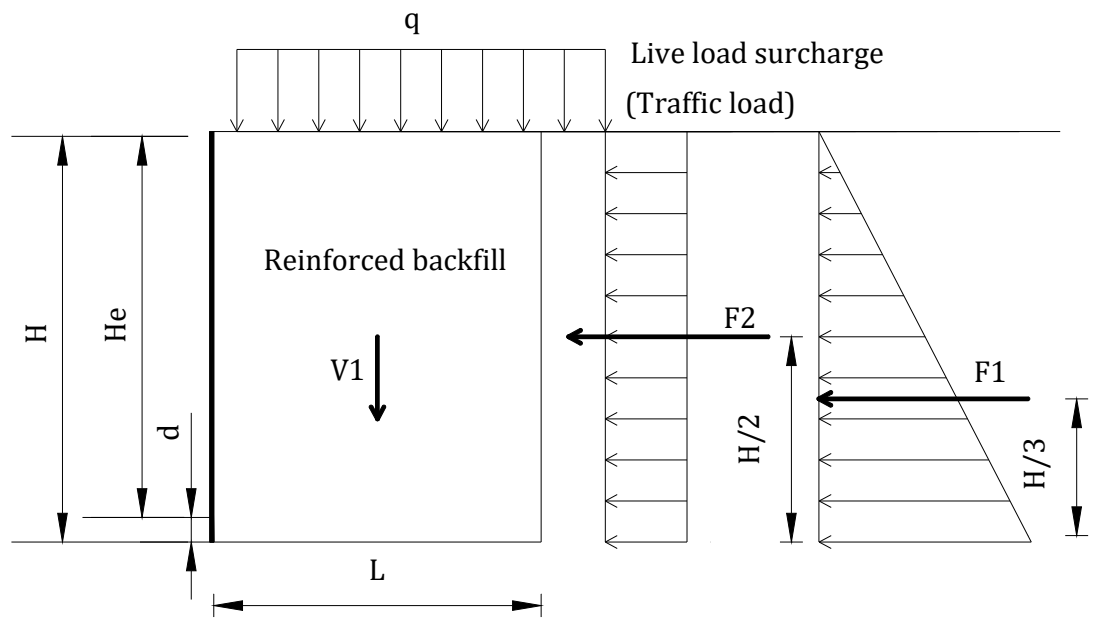

Figure 2 - External stability analysis: nominal earth pressures for MSE walls with level backfill and traffic load

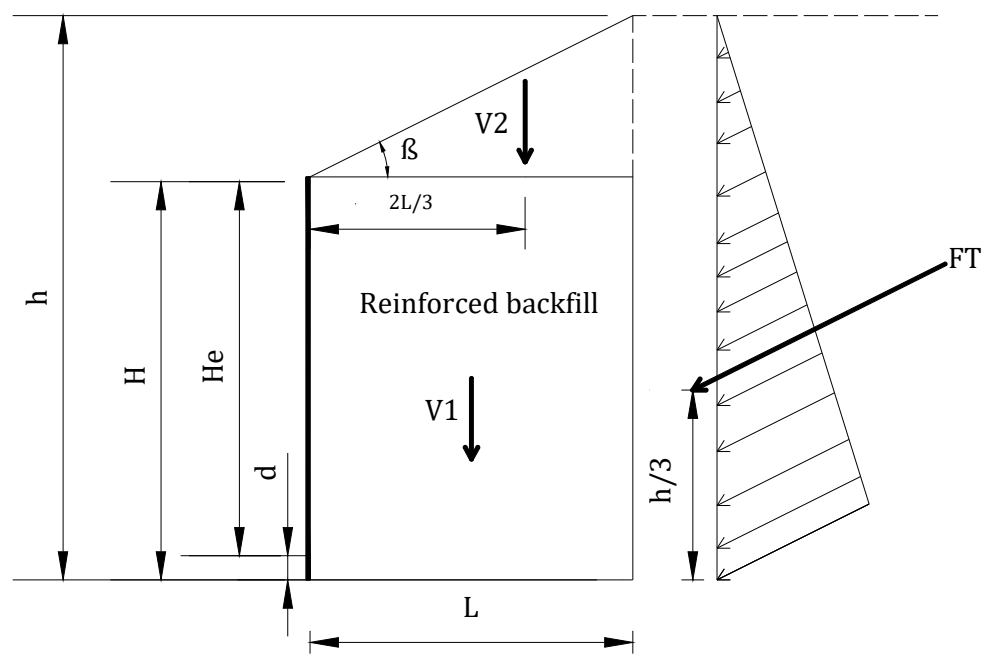

Figure 3 - External stability analysis: earth pressure for MSE walls with sloping backfill

$F_{1}=\frac{1}{2} K_{a b} \gamma_{b} H^{2}$

$F_{2}=K_{a b} q H$

$F_{T}=\frac{1}{2} K_{a b} \gamma_{b} h^{2}$ 
where, $\gamma_{b}$ and $q$ are moist unit weight of the retained backfill soil and the uniform live load surcharge, respectively. $\mathrm{H}$ is the height of the retaining wall and $\mathrm{h}$ is defined as the summation of the total height of the wall, $\mathrm{H}$, and the slope at back of the reinforced zone. $K_{a b}$ is the active earth pressure coefficient for the retained backfill calculated according to Eqs. (4-5).

$K_{a b}=\frac{\sin ^{2}\left(\theta+\varnothing_{b}^{\prime}\right)}{\Gamma \sin ^{2}(\theta) \sin (\theta-\delta)}$

$\Gamma=\left(1+\sqrt{\frac{\sin \left(\varnothing^{\prime}{ }_{b}+\delta\right) \sin \left(\varnothing^{\prime}{ }_{b}-\beta\right)}{\sin (\theta-\delta) \sin (\theta+\beta)}}\right)^{2}$

where $\beta, \delta$ and $\theta$ are nominal slope of backfill behind the wall, angle of friction between retained backfill and reinforced soil, and inclination of the wall, respectively. Here, $\varnothing^{\prime}{ }_{b}$ is the effective friction angle of retained backfill in degrees. In the present study, the factored horizontal driving forces for MSE walls are computed according to Eqs. (6).

$P_{d}=\gamma_{E H} F_{1}+\gamma_{L L} F_{2}$

In this equation $P_{d}$ denotes the factored horizontal driving force for MSE wall with level backfill and uniform live load, where $\gamma_{E H}$ and $\gamma_{L L}$ are the load factors for different load combinations presented in Table 1 . In case of MSE walls with sloping backfill $P_{d}$ will be determined as follows.

$P_{d}=\gamma_{E H} F_{H}$

$F_{H}=F_{T} \cos \beta$

where $F_{H}$ is the horizontal component of earth pressure from retained backfill, $F_{T}$. After calculation of driving forces, nominal $\left(R_{r}\right)$ and factored resistance $\left(R_{R}=\emptyset_{r} R_{r}\right)$ against sliding are calculated. Generally, resistance factors $(\varnothing)$ depend on the wall type, stability mode, material type and loading conditions. In this study the corresponding resistance factors for bearing resistance and sliding are set to 0.65 and 1.00, respectively AASHTO (2010) [18].

Table 1 - Summary of load factors used for design [3]

\begin{tabular}{|l|l|l|l|}
\hline Load combination & $\gamma_{E V}$ & $\gamma_{E H}$ & $\gamma_{L L}$ \\
\hline Strength I (max) & 1.35 & 1.50 & 1.75 \\
\hline Strength I (min) & 1.00 & 0.90 & 1.75 \\
\hline Service I & 1.00 & 1.00 & 1.00 \\
\hline
\end{tabular}

Furthermore, the factored resistance for MSE walls with sloping backfill is calculated using Eq. (9).

$R_{r}=\left\{\gamma_{E V}\left(V_{1}+V_{2}\right)+\gamma_{E H} F_{T} \sin \beta\right\} \mu$ 
In Eqs. (9), $\mu$ is the tangent of the minimum friction angle, $\beta$ is the inclination of the sloping backfill. Here, $V_{1}$ and $V_{2}$ are the vertical loads at the base of the MSE wall due to the reinforced soil zone and sloping backfill, respectively (Figure 3). In case of MSE walls with level backfill and uniform live load surcharge, $\mathrm{Rr}$ is computed using the following equation.

$R_{r}=\gamma_{E V} V_{1} \mu$

Regarding the factored loads and resistance forces, the capacity demand ratio (CDR) for sliding is then determined based on the ratio of the factored resistance forces to the computed factored loads. It is apparent that the factored resistances must be greater than the factored loads i.e. $\mathrm{CDR} \geq 1$.

The eccentricity limit criterion is another external stability check that must be considered. Here, the eccentricity of the MSE walls is calculated by dividing the net moment, which is the difference between the driving and resisting moments with respect to the toe of the wall, by the vertical load. With respect to the type of foundation, two different eccentricity criteria are considered in the present study for soil and rock foundations. Accordingly, the maximum eccentricity $\left(e_{\max }\right)$ is limited to $1 / 4$ and $3 / 8$ of the base width for soil and rock foundations, respectively [18].

Another external stability check is to investigate the bearing capacity of foundation soil. Bearing capacity evaluations are carried out for strength as well as service limit states. Here, for strength limit state calculations, factored loads and resistances are considered, whereas in case of service limit state calculations nominal forces and capacities are taken into account. The vertical stress $\left(\sigma_{v}\right)$ due to the presence of the MSE wall is determined as follows (Eq. 11).

$\sigma_{v}=\frac{\Sigma V}{L-2 e_{B}}$

In this equation, $\Sigma V$ is the sum of factored vertical forces, $L$ is the width of foundation, and $e_{B}$ is eccentricity for bearing calculation. The bearing pressure at the base of the wall computed using the factored loads are compared to the factored bearing resistance $\left(q_{R}\right)$ (Eq.12).

$q_{R}=\varnothing q_{n}$

where, $\varnothing$ is the resistance factor, and $q_{n}$ is the nominal bearing resistance of the soil/rock foundation. The capacity demand ratio (CDR) for bearing capacity is then calculated based on the factored bearing resistance $\left(q_{R}\right)$ and factored bearing stress $\left(\sigma_{v}\right)$.

In this study, settlement analyses are also carried out and the results obtained are compared to the allowable limits. Although conventional settlement analyses can be performed, the settlement is evaluated at Service I limit state [2,3]. For bearing capacity calculations based on Service I limit state, the bearing stress at the bottom of the wall is limited to the nominal bearing capacity of the soil. More specifically, through checking this criterion the settlement under the footing is limited to $2.54 \mathrm{~cm}$. 


\subsection{Internal Stability Analyses}

In case of internal stability analyses, two failure modes, namely breakage and pull out of the reinforcement due to the tensile forces should be checked. For internal stability assessments, the reinforced zone is divided into active and resistant zones based on a failure surface. In the present study, inextensible metal strips are used to reinforce the MSE walls, and the potential failure surface for walls with inextensible inclusions are depicted in Figure 4 based on Ref. [18].

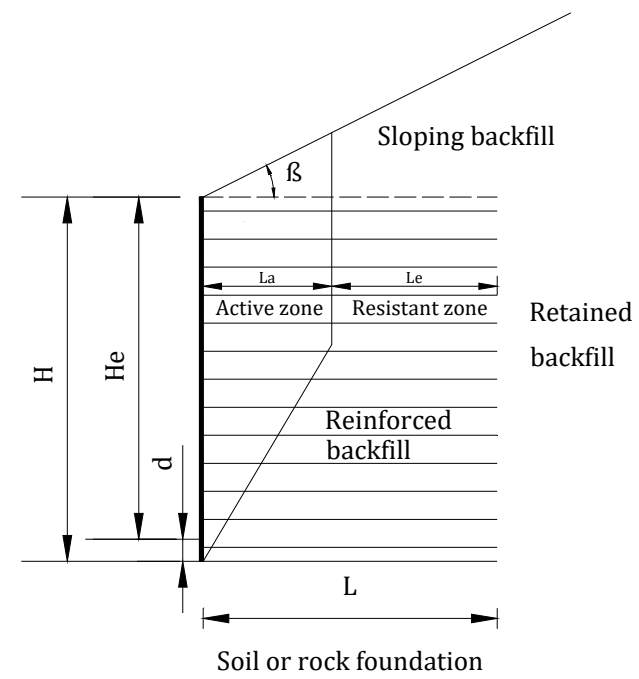

Figure 4 - Internal stability analysis: potential failure surface for walls with inextensible reinforcements.

The lateral pressure that is used to determine the maximum tension developed is determined using the simplified method $[2,18]$. As presented in Figure 5 the lateral stress ratio $K_{r} / K_{a}$ varies with depth. The active earth pressure coefficient, $K_{a}$ and the horizontal stresses, $\sigma_{H}$, at each reinforcement layer within the reinforced soil zone for a vertical MSE wall is determined using the Rankine equation (Eqs.13-14).

$$
\begin{gathered}
K_{a}=\tan ^{2}\left(45-\frac{\emptyset_{r}^{\prime}}{2}\right) \\
\sigma_{H}=K_{r}\left(\sigma_{V}\right)+\Delta \sigma_{H}
\end{gathered}
$$

where, $\emptyset^{\prime}{ }_{r}$ is the internal friction angle of the reinforced fill, $K_{r}$ is the coefficient of lateral earth pressure in the reinforced soil zone, $\sigma_{V}$ is the factored vertical pressure at the depth of interest, and $\Delta \sigma_{H}$ is the supplemental factored horizontal stress due to external surcharges. 


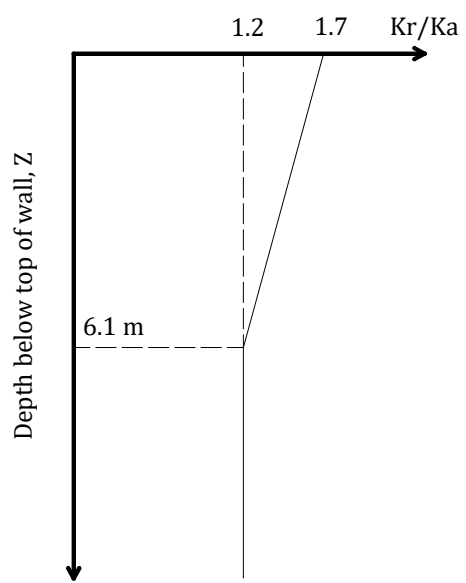

Figure 5 - Variation of the coefficient of lateral stress ratio $K_{r} / K_{a}$ with depth for MSE walls with ribbed steel strips [18].

The maximum tension $\left(T_{\max }\right)$ in each reinforcement layer is determined by multiplying the tributary area by horizontal stress. The factored reinforcement tensile and pullout resistances are then compared with $T_{\max }$ to finalize the reinforcement pattern. In the present work, galvanized ribbed steel strips are used as reinforcement and their resistances are calculated based on 75 years of design life. Regarding the recommendations of AASHTO (2010) [18], the steel corrosion rates for the first two years are taken as $15 \mu \mathrm{m} /$ year and thereafter 4 $\mu \mathrm{m} /$ year per side. The nominal tensile resistance $\left(T_{r}\right)$ is also calculated based on the crosssectional area at the end of the service life and yield strength of the utilized steel. The tensile resistance factor is taken as 0.75 [18] and the factored resistance $\left(T_{r r}\right)$ is calculated by multiplying the nominal resistance by this factor.

In the course of assessment for internal stability, the pullout failure check is also accomplished. The nominal pullout resistance $\left(P_{r}\right)$ is determined based on the reinforcement type, vertical stress acting on the reinforcement, and the factor $F^{*}$ (Figure 6). The factored resistance $\left(P_{r r}\right)$ is computed as follows [18].

$P_{r}=\alpha F^{*}(2 b)\left(L_{e}\right)\left(\sigma_{v-\text { soil }}\right) \gamma_{E V}$

$P_{r r}=\emptyset P_{r}$

In Eqs (15-16), $\varnothing=0.90$ is the resistance factor for soil reinforcement pullout, $\alpha$ is the scale correction factor (set to 1 for inextensible reinforcements), $F^{*}$ is pullout resistance factor calculated in any depth within the reinforced backfill (see Figure 5), b and $L_{e}$ are the width and length of the reinforcement in the resisting zone, respectively. Here, $\sigma_{v \text {-soil }}$ is the soil load of the reinforced mass. Based on the maximum tension in each reinforcement, $T_{\max }$, the factored tensile resistance, $T_{r r}$, and the factored pullout resistance $P_{r r}$, the number of strip reinforcements are calculated and the reinforcement pattern is determined. Generally, availability of different types of metal reinforcements as well as reinforced backfill soils 
arises the need for decision making on the best solution among the numerous candidate designs for a MSE wall. Hence, to obtain a cost-effective design employing an optimization technique seems to be fruitful.

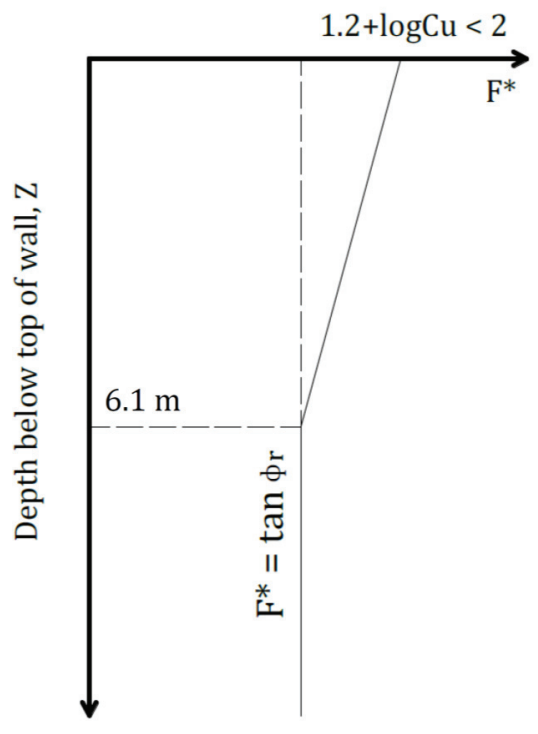

Figure $6-F^{*}$ parameter for MSE walls with ribbed steel strips [18].

\section{OPTIMIZATION PROBLEM FORMULATION}

Optimum design of structural systems entails decision making on the best values of the involved design variables. Meanwhile, the final design must satisfy the design constraints stipulated by a standard code of practice. Mathematically, the minimum cost design of a MSE wall considering the cost of steel strip reinforcements as well as the reinforced backfill soil can be stated as follows:

Find $\quad X^{T}=\left[x_{1}, x_{2}, \ldots, x_{n v}\right]$

such that $X$, including $n v$ design variables, minimizes the following cost objective function, $C(X)$ :

$C(X)=V_{\text {soil }} C_{\text {soil }}+W_{\text {steel }} C_{\text {steel }}$

where $V_{\text {soil }}$ is the total volume of the backfill soil, $C_{\text {soil }}$ is the cost per unit volume of the backfill soil, $W_{\text {steel }}$ is the total weight of the steel reinforcements, and $C_{\text {steel }}$ is the cost per unit weight of the reinforcements. Here, the minimum cost design of MSE walls is subjected to the design constraints described in the previous section. It follows that, an optimization algorithm capable of handling the aforementioned constraints is adopted for an efficient search in the solution space. 


\section{ADAPTIVE DIMENSIONAL SEARCH ALGORITHM}

Adaptive dimensional search was first presented in Ref. [17] for design optimization of truss structures. This population based optimization technique is working based on an evolutionary approach where at each iteration, after evaluation of the generated candidate designs, the best design found is used to generate a new population of candidate designs. The robustness of the adaptive dimensional search algorithm lies in the idea of updating the search dimensionality ratio (SDR) parameter dynamically during the optimization process to achieve a satisfactory balance between the exploration and exploitation features of the technique. In general, SDR can be defined as the percentage of the design variables that are perturbed probabilistically while generating a candidate solution from the current best design as follows:

$$
S D R=\frac{N_{p}}{N_{m}}
$$

where $N_{p}$ is the number of design variables perturbed for generating a new candidate design and $N_{m}$ is the total number of design variables. If SDR is different for each candidate design, the average search dimensionality ratio for a population, $(S D R)_{\text {ave }}$, can be determined using the mean of $S D R$ values of all the candidate designs, (Eq. 20).

$$
(S D R)_{a v e}=\frac{\sum_{j=1}^{N_{p o p}}(S D R)_{j}}{N_{p o p}}
$$

In Eq. (20), $(S D R)_{j}$ is search dimensionality ratio for the solution $\mathrm{j}$ and $N_{\text {pop }}$ is the size of population. The general outline of the $A D S$ algorithm is elaborated in the following steps.

Step 1. Initial population: Generate an initial population by randomly spreading candidate solutions over the search space in a uniform manner.

Step 2. Evaluation: Evaluate the corresponding objective function value of each candidate solution. The corresponding objective function values of the feasible solutions are computed using Eq. (18). However, infeasible designs that violate the constraints of the optimization problem are penalized, and their objective function values are determined based on Eq. (21).

$$
C_{p}(X)=C(X)\left[1+p\left(\sum_{i} g_{i}\right)\right]
$$

In Eq. (21), $C(X)$ is the cost objective function defined in Eq. (20), $C_{p}(X)$ is the penalized objective function, $\mathrm{g}_{i}$ is the $i$-th problem constraint violation and $p$ is the penalty constant employed for constraint handling.

Step 3. Adapting search dimensionality ratio: Determine the value of $(S D R)_{\text {ave }}$, for perturbation of candidate designs in the next step, with respect to the success of the ADS in improving the current best solution as follows. 
$(S D R)_{\text {ave }}^{(i t+1)}=\left\{\begin{array}{lc}\frac{(S D R)_{\text {ave }}^{(i t)}}{\lambda} & \text { if the best solution is improved } \\ \lambda(S D R)_{\text {ave }}^{(i t)} & \text { if the best solution is not improved }\end{array}\right.$

Considering Eq. (22) if the best candidate solution found so far is improved in the current iteration, (it), then the value of $(S D R)_{a v e}$ is increased for the next iteration, (it +1$)$, through dividing its value by an adaptation factor, $\lambda$ (taken as 0.98 in this study), otherwise (SDR) ave is decreased through multiplying its value by $\lambda$. The high values of SDR yield a more explorative search strategy by enabling moves in the search space through the change of many design variables at a time, resulting in large, yet relatively unfettered step sizes. Meanwhile, the low values of SDR lead to a more explorative search by facilitating small, yet more conservative moves in the design space. The rationale behind Eq. (22) is to promote a more explorative search, if any of the moves in the previous iteration leads to an improved solution. This way the search dimension is increased and the algorithm is encouraged to discover new solutions in an extended region of the search space. On the other hand, if the previous iteration leads to no improvement, diverse search is somewhat limited, and the algorithm is biased towards sampling by small and judicious moves around the current design. This way the SDR parameter is updated at each iteration to benefit from a more explorative or exploitative search alternately for the most efficient optimization process. In the present study the initial value of the $(S D R)_{\text {ave }}$ is set to 0.25 , and the upper and lower bounds on the values of $(S D R)_{\text {ave }}$ are set to 0.5 and $\frac{1}{N_{m}}$, respectively, where $N_{m}$ is the number of solution variables.

Step 4. Generation phase: Generate new candidate solutions based on the selected SDR in the previous step. Here, Eq. (23) is used at each iteration to produce new solutions around the current best solution.

$$
X_{i}^{\text {new }}=X_{i}^{c}+\operatorname{round}\left[N(0,1)_{i}\left(\sqrt{\left(X_{i}^{\max }-X_{i}^{\min }\right)}-\left(\sqrt{\left(X_{i}^{\max }-X_{i}^{\min }\right)}-1\right) \frac{i t}{\max _{-} i t}\right)\right]
$$

where $X_{i}^{c}$ is the value of $\mathrm{i}$-th discrete design variable in the best candidate solution, and $X_{i}^{\min }$ and $X_{i}^{\max }$ are its lower and upper bounds, respectively. $\mathrm{N}(0,1)_{i}$ is a random number generated according to a standard normal distribution with mean $(\mu)$ zero and standard deviation $(\sigma)$ equal to one, it is the iteration number, and max $i t$ is the maximum number of iterations. It is obvious that in the generation phase, in order to take the value of $S D R$ into account, only some of the solution variables are selected and changed through Eq. (23).

Step 5. Elitism: Keep the current best solution in a separate place or as a member of the population.

Step 6. Termination: Go to Step 2 until a termination criterion is satisfied. In this study, a maximum number of iterations is considered as the termination criterion for the optimization process. It is worthwhile to note that, to further improve the performance of the ADS, different stagnation control strategies have been proposed in Ref. [17]. Here, the aforementioned steps are followed for implementation of the algorithm. 


\section{NUMERICAL EXAMPLES}

This section covers the numerical experiments performed using practical examples of MSE walls under different cases. In the first design example a MSE wall with sloping backfill is optimally designed under the aforementioned design constraints. In the second example, a MSE wall with level backfill is optimally designed under traffic load. Each test instance is tackled in two different cases where in the first case (case-a) the MSE wall rests on a soil foundation, whereas in the second case (case-b) the wall is assumed to be on a rock foundation.

For design optimization, the ADS algorithm is executed using a population size of 25 individuals over 200 iterations. It is apparent that due to the stochastic nature of the optimization algorithm it is expected to obtain different solutions from independent runs of the algorithm. In this study, for each test instance the ADS optimization algorithm is independently executed 100 times, and the best solution obtained is reported as the minimum cost design. Here, a discrete optimization is performed where the algorithm selects the type of ribbed steel strip and reinforced backfill soil form the available lists provided in Tables 2 and 3. For all the investigated examples the coefficient of uniformity of the reinforced backfill soil is assumed to be $C_{u}=7$. For practical requirements, the optimal spacing and length of the strips are selected from multiplies of $0.02 \mathrm{~m}$. For all the investigated MSE walls a panel width of $W_{p}=1.5 \mathrm{~m}$ is chosen for the precast facing elements.

\subsection{Example 1: MSE Wall with Sloping Backfill}

The $9.14 \mathrm{~m}$ high vertical MSE wall shown in Figure 7 is considered as the first design instance. The exposed height of the structure above the finished grade $\left(H_{e}\right)$ and its embedment depth $(d)$ are $8.61 \mathrm{~m}$ and $0.53 \mathrm{~m}$, respectively. In this example, the ground surface slopes behind the wall with an angle of $\beta=26.56^{\circ}$. For reinforcing the wall, ribbed steel strips as inextensible reinforcements are used in this example. Generally, in case of metallic inclusions, corrosion resistance is an important parameter affecting the life of the structure. Here, expecting a service life of 75 years for the MSE wall, galvanized ribbed steel strips with zinc coating of $86 \mu \mathrm{m}$ are utilized. As suggested in Ref. [2], the lower bound on the length of steel strips is set to $0.8 H$ where $H$ is the total height of the MSE wall. The material properties and costs of the available ribbed steel strips are presented in Table 2.

Table 2 - Material properties and costs of the available ribbed steel strips

\begin{tabular}{|c|c|c|c|c|c|c|}
\hline $\begin{array}{c}\text { Strip } \\
\text { type }\end{array}$ & Designation & $\begin{array}{c}\mathrm{b} \\
(\mathrm{mm})\end{array}$ & $\begin{array}{c}\mathrm{t} \\
(\mathrm{mm})\end{array}$ & $\begin{array}{c}f_{y} \\
(\mathrm{MPa})\end{array}$ & $\begin{array}{c}\rho \\
\left(\text { ton } / \mathrm{m}^{3}\right)\end{array}$ & $\begin{array}{c}\text { Cost } \\
(\$ / \mathrm{kg})\end{array}$ \\
\hline 1 & ST-1 & 40 & 4 & 448.16 & 7.92 & 1.95 \\
\hline 2 & ST-2 & 40 & 4 & 509.87 & 8.12 & 2.00 \\
\hline 3 & ST-3 & 40 & 5 & 448.16 & 7.92 & 1.90 \\
\hline 4 & ST-4 & 40 & 5 & 509.87 & 8.12 & 2.00 \\
\hline 5 & ST-5 & 45 & 4 & 448.16 & 7.92 & 1.90 \\
\hline 6 & ST-6 & 45 & 4 & 509.87 & 8.12 & 2.10 \\
\hline
\end{tabular}


Table 2 - Material properties and costs of the available ribbed steel strips (continue)

\begin{tabular}{|c|c|c|c|c|c|c|}
\hline $\begin{array}{c}\text { Strip } \\
\text { type }\end{array}$ & Designation & $\begin{array}{c}\mathrm{b} \\
(\mathrm{mm})\end{array}$ & $\begin{array}{c}\mathrm{t} \\
(\mathrm{mm})\end{array}$ & $\begin{array}{c}f_{y} \\
(\mathrm{MPa})\end{array}$ & $\begin{array}{c}\rho \\
\left(\text { ton } / \mathrm{m}^{3}\right)\end{array}$ & $\begin{array}{c}\text { Cost } \\
(\$ / \mathrm{kg})\end{array}$ \\
\hline 7 & ST-7 & 45 & 5 & 448.16 & 7.92 & 1.95 \\
\hline 8 & ST-8 & 45 & 5 & 509.87 & 8.12 & 2.05 \\
\hline 9 & ST-9 & 50 & 4 & 448.16 & 7.92 & 1.90 \\
\hline 10 & ST-10 & 50 & 4 & 509.87 & 8.12 & 2.00 \\
\hline 11 & ST-11 & 50 & 5 & 448.16 & 7.92 & 1.95 \\
\hline 12 & ST-12 & 50 & 5 & 509.87 & 8.12 & 2.00 \\
\hline 13 & ST-13 & 55 & 4 & 509.87 & 8.12 & 2.05 \\
\hline 14 & ST-14 & 55 & 5 & 509.87 & 8.12 & 2.05 \\
\hline 15 & ST-15 & 60 & 4 & 509.87 & 7.92 & 2.10 \\
\hline 16 & ST-16 & 60 & 5 & 509.87 & 8.12 & 2.10 \\
\hline
\end{tabular}

It is generally known that in the MSE walls the performance of reinforcement mainly depends on the friction characteristics of the fill. It follows that the reinforced fill is preferred to be a well-graded soil due to its favorable strength, drainage, placement, and compaction properties. Here, the properties and costs of available soils to be used in the reinforced zone are presented in Table 3. It is worthwhile to note that shear strength parameters of the retained backfill -the fill material located behind the mechanically stabilized soil zone- are also important in the design stage to determine the coefficients of earth pressure. In this test example, friction angle and unit weight of the retained filled are taken as $\emptyset_{f}=30^{\circ}$ and $\gamma_{f}=$ $19.64 \mathrm{kN} / \mathrm{m}^{3}$, respectively.

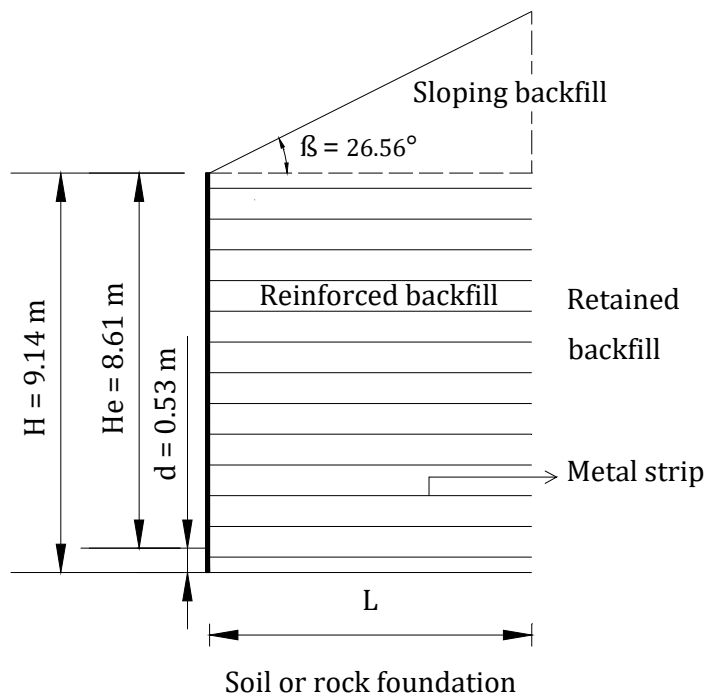

Figure 7 - MSE wall system of test example 1. 
Table 3 - Properties and costs of the available reinforced backfill soils

\begin{tabular}{|c|c|c|c|c|}
\hline $\begin{array}{l}\text { Reinforced } \\
\text { backfill type }\end{array}$ & Designation & $\phi_{r}$ & $\begin{array}{c}\gamma_{\mathrm{r}} \\
\left(\mathrm{kN} / \mathrm{m}^{3}\right)\end{array}$ & $\begin{array}{c}\text { Cost } \\
\left(\$ / \mathrm{m}^{3}\right)\end{array}$ \\
\hline 1 & RB-1 & $34^{\circ}$ & 18.06 & 17.5 \\
\hline 2 & RB-2 & $36^{\circ}$ & 18.22 & 17.5 \\
\hline 3 & RB-3 & $38^{\circ}$ & 18.54 & 18.0 \\
\hline 4 & RB-4 & $40^{\circ}$ & 19.48 & 18.5 \\
\hline 5 & RB-5 & $42^{\circ}$ & 19.95 & 19.5 \\
\hline
\end{tabular}

This test problem is solved in two different cases where in the first case (case-a) the MSE wall rests on a soil foundation, whereas in the second case (case-b) the wall is assumed to be located on a rock foundation. In case-a the foundation soil has a friction angle of $\emptyset_{\mathrm{fd}}=30^{\circ}$, and a unit weight of $\gamma_{f d}=19.64 \mathrm{kN} / \mathrm{m}^{3}$. The factored bearing resistance of the foundation soil is assumed to be $359 \mathrm{kPa}$ and $502 \mathrm{kPa}$ for service and strength limit considerations, respectively.

Minimum cost design of the MSE wall with sloping backfill is performed using the ADS algorithm and the results obtained for case-a are summarized in Table 4. As presented in the table the ADS algorithm finds a promising final design with a cost of $\$ 418539.25$ in case-a. In the optimum solution obtained, RB-2 is selected as the reinforced backfill soil type, and ST-2, with a length of $\mathrm{L}=7.32 \mathrm{~m}$ and a vertical spacing of $\mathrm{S}_{\mathrm{v}}=0.88 \mathrm{~m}$, is adopted as the steel reinforcement for the investigated MSE wall. As given in Table 4 the horizontal spacing of strips $\left(\mathrm{S}_{h}\right)$ may vary for different strip layers.

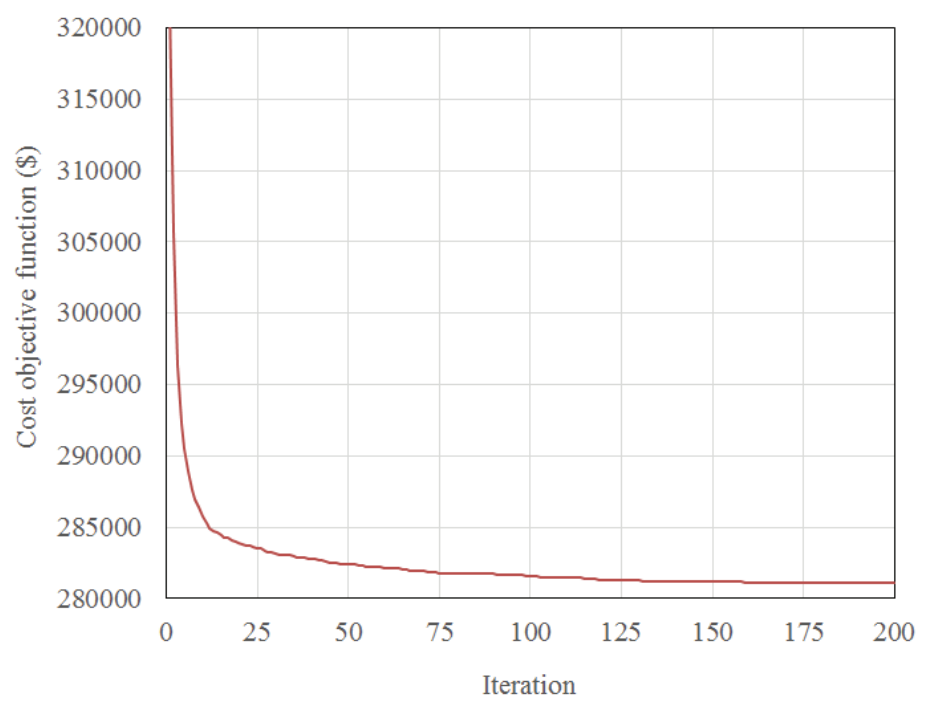

Figure 8 - Cost optimization history of test example 1-case (b) 


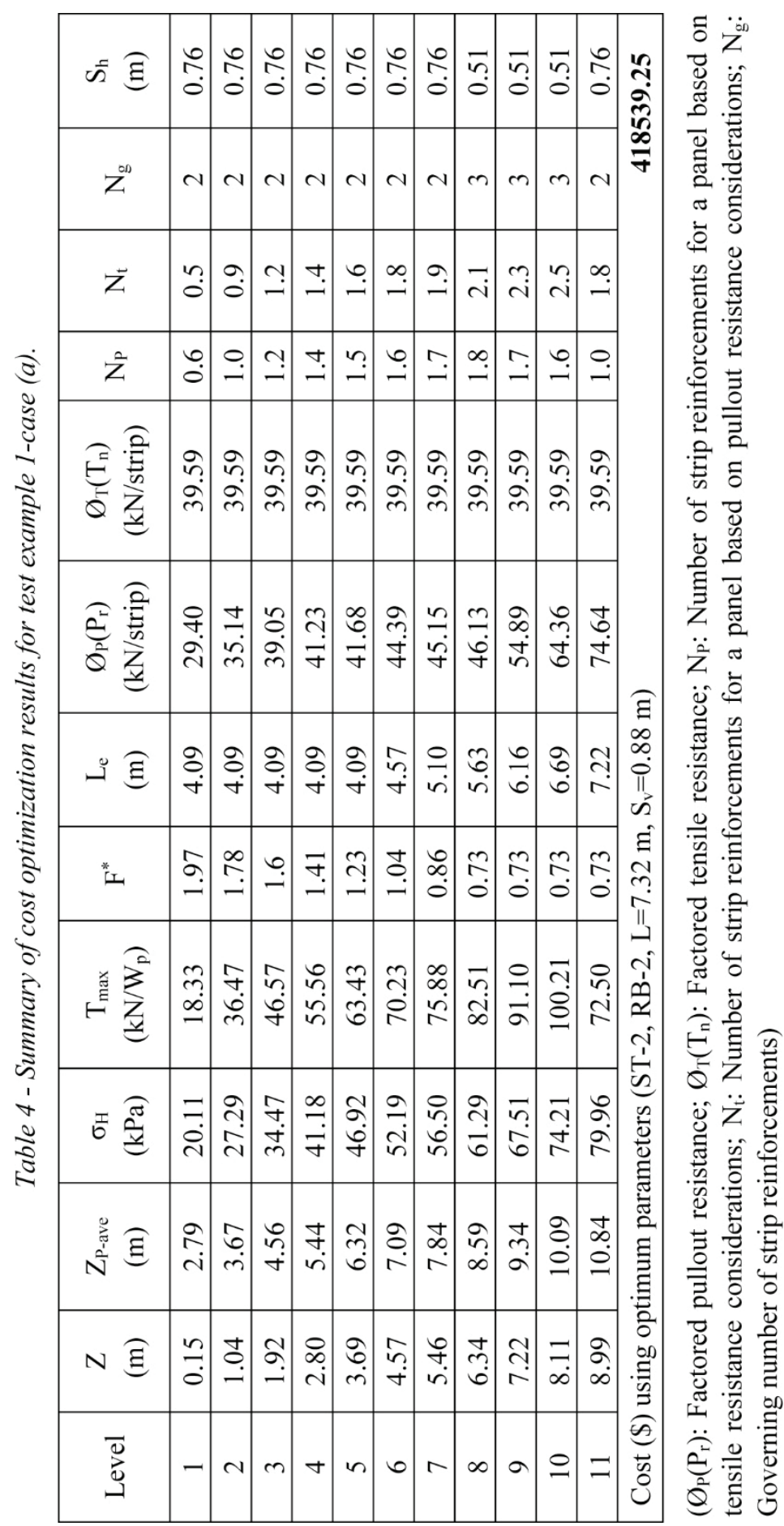




\begin{tabular}{|c|c|c|c|c|c|c|c|c|c|c|c|c|c|c|c|}
\hline$\tilde{\omega} \widehat{\Xi}$ & $\begin{array}{l}0 \\
0 \\
0\end{array}$ & $\tilde{n}$ & $\tilde{n}$ & $\tilde{n}$ & $\underset{\sim}{\infty}$ & $\bar{c}$ & & $\overline{0}$ & $\tilde{n}$ & $\stackrel{0}{\circ}$ & 일 & م. & 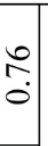 & $\frac{m}{\frac{\pi}{\sigma}}$ & 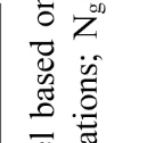 \\
\hline$z^{\infty}$ & $N$ & $m$ & $m$ & $m$ & $\checkmark$ & $c$ & & $m$ & $m$ & $N$ & 0 & & $N$ & & 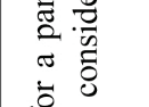 \\
\hline $\overrightarrow{\mathrm{Z}}$ & $\tilde{o}$ & $\stackrel{\infty}{0}$ & $\hat{0}$ & 二 & ? & 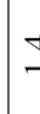 & & $?$ & $\stackrel{0}{-}$ & $\stackrel{\infty}{-}$ & $c$ & & $\stackrel{\infty}{-}$ & & 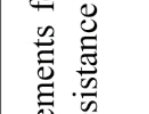 \\
\hline$\hat{z}$ & $\stackrel{\circ}{\sim}$ & $\dddot{n}$ & $\stackrel{\Upsilon}{\sim}$ & حે & ले & ? & & $\stackrel{n}{\sim}$ & $\overrightarrow{\mathrm{i}}$ & $\stackrel{\infty}{-}$ & 1 & $\begin{array}{llll} & \\
& \end{array}$ & $\stackrel{\sim}{ִ}$ & & 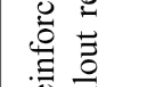 \\
\hline き高 & $\begin{array}{l}\stackrel{0}{2} \\
\stackrel{y}{y}\end{array}$ & ڤே & $\stackrel{\circ}{n}$ & ค̊ & ค & ç & & 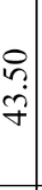 & 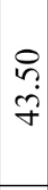 & ก & s & & 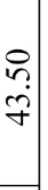 & & 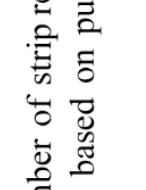 \\
\hline 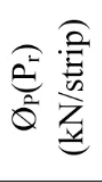 & ?. & 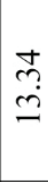 & $\stackrel{\infty}{+}$ & శ̊ & $\begin{array}{l}0 \\
1 \\
I\end{array}$ & in & & $\begin{array}{l}\hat{b} \\
\infty \\
\infty \\
\end{array}$ & $\begin{array}{l}n \\
m \\
m\end{array}$ & $\begin{array}{l}\infty \\
\infty \\
\stackrel{\gamma}{+}\end{array}$ & is & & 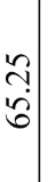 & § & $\begin{array}{l}\Xi \bar{\Xi} \\
\bar{\Xi} \\
\ddot{\Xi} \\
\ddot{z} \\
\ddot{\theta} \\
\dot{\theta}\end{array}$ \\
\hline$\bumpeq \widehat{\Xi}$ & $\stackrel{n}{n}$ & $\tilde{n}$ & กี & กํ & ? & 2 & & $\tilde{n}$ & $\begin{array}{l}\infty \\
\infty \\
i\end{array}$ & ণे & 0 & $\hat{r}$ & $\begin{array}{c}\stackrel{N}{+} \\
+\end{array}$ & $\begin{array}{l}\infty \\
\infty \\
0 \\
\dot{0} \\
\dot{n} \\
\tilde{\varepsilon}\end{array}$ & 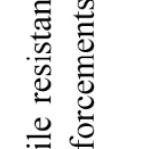 \\
\hline 瓶 & $\stackrel{ \pm}{\Delta}$ & $\stackrel{\infty}{\underset{\sim}{\sim}}$ & ర్ & $\stackrel{\sim}{\sim}$ & กิ & 7 & $\stackrel{2}{-}$ & $\hat{\sigma}$ & $\begin{array}{l}+ \\
\infty \\
0\end{array}$ & $\underset{0}{\infty}$ & $\varnothing$ & $\begin{array}{l}0 \\
0 \\
0 \\
\\
\end{array}$ & $\begin{array}{l}\dot{D} \\
\dot{0}\end{array}$ & $\begin{array}{l}\overrightarrow{8} \\
\dot{0} \\
\dot{H}\end{array}$ & 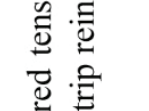 \\
\hline 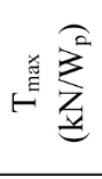 & 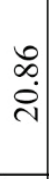 & $\begin{array}{l}\infty \\
\infty \\
\infty\end{array}$ & 呈 & $\begin{array}{l}n \\
n \\
\infty \\
+\end{array}$ & $\begin{array}{l}0 \\
0 \\
n\end{array}$ & f & & $\begin{array}{l}\vec{\nabla} \\
\dot{\sigma} \\
\dot{0}\end{array}$ & \begin{tabular}{l}
0 \\
$\infty$ \\
0 \\
\hdashline
\end{tabular} & ñ & w & $\begin{array}{l}0 \\
\vdots \\
\vdots \\
0\end{array}$ & $\begin{array}{l}\stackrel{ }{+} \\
2 \\
\end{array}$ & 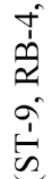 & 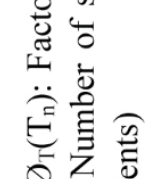 \\
\hline 可 & $\begin{array}{l}\hat{\sigma} \\
\infty\end{array}$ & $\begin{array}{l}\infty \\
? \\
\sim\end{array}$ & $\frac{8}{8}$ & ñ & $\frac{m}{7}$ & ร & 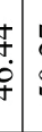 & 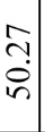 & $\begin{array}{l}\infty \\
n \\
\sim \\
n\end{array}$ & $\begin{array}{l}n \\
\infty \\
\infty \\
n\end{array}$ & $\begin{array}{l}8 \\
8 \\
6\end{array}$ & 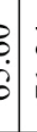 & $\frac{\tilde{T}}{n}$ & 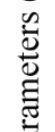 & 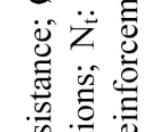 \\
\hline 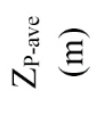 & 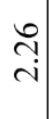 & $\frac{N}{m}$ & $\hat{\sigma}$ & $\begin{array}{l}\infty \\
\stackrel{+}{~}\end{array}$ & $\underset{v}{\infty}$ & 7 & & $\frac{m}{\sim}$ & $\begin{array}{l}0 \\
\infty \\
-\end{array}$ & $\begin{array}{l}\infty \\
\infty \\
\infty\end{array}$ & o & $?$ & $\begin{array}{l}\hat{2} \\
0 \\
0\end{array}$ & 亲 & 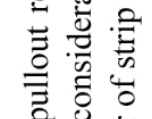 \\
\hline$N \Xi$ & $\begin{array}{c}0 \\
? \\
0\end{array}$ & $\stackrel{0}{=}$ & $\underset{\mathrm{i}}{\overline{\mathrm{j}}}$ & $\begin{array}{l}\infty \\
\infty \\
\sim\end{array}$ & ल & is & 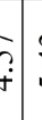 & $\begin{array}{l}\stackrel{f}{f} \\
\dot{r}\end{array}$ & 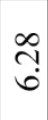 & $\frac{n}{\pi}$ & r & $\hat{0}$ & $\begin{array}{l}+ \\
\infty \\
\infty \\
\infty\end{array}$ & . & 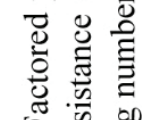 \\
\hline D্] & - & $N$ & $m$ & $\nabla$ & $n$ & 6 & & $r$ & $\infty$ & 0 & $S$ & & $=$ & 范 & 产 \\
\hline
\end{tabular}


As already noted, in case-b the foundation is selected as rock. Base on this assumption, the internal friction angle and allowable bearing pressure of the rock foundation are taken as $45^{\circ}$ and $10 \mathrm{MPa}$, respectively. It should be noted that in case-b the lower bound on the length of steel strips is set to $0.4 H$ where $H$ is the total height of the MSE wall [2]. The numerical results of optimization in case-b for the MSE wall with sloping backfill are tabulated in Table 5. In this case a minimum cost of $\$ 280219.13$ is obtained for the final design. For the optimum solution the ADS finds RB-4 as the reinforced backfill soil type, and ST-9, with a length of $L=4.60 \mathrm{~m}$ and a vertical spacing of $\mathrm{S}_{v}=0.85 \mathrm{~m}$, as the steel reinforcement of the wall. The average cost optimization history of 100 independent runs of the ADS are plotted in Figure 8. The comparison of final results obtained in two different cases indicates a reduction of $33 \%$ in the cost of the MSE wall in case-b compared to case-a.

\subsection{Example 2: MSE Wall with Level Backfill And Traffic Load}

Minimum cost design of the MSE wall depicted in Figure 9, with level backfill and traffic load, is considered as the second test example. Here, similar to the previous test example in case-a the foundation soil has a friction angle of $\varnothing_{\mathrm{fd}}=30^{\circ}$, and a unit weight of $\gamma_{f d}=19.64$ $\mathrm{kN} / \mathrm{m}^{3}$. The factored bearing resistance of the foundation soil is also assumed to be $359 \mathrm{kPa}$ and $502 \mathrm{kPa}$ for service and strength limit considerations, respectively. In this case, the lower bound on the length of steel strips is set to $0.7 H$ where $H$ is the total height of the MSE wall [2].

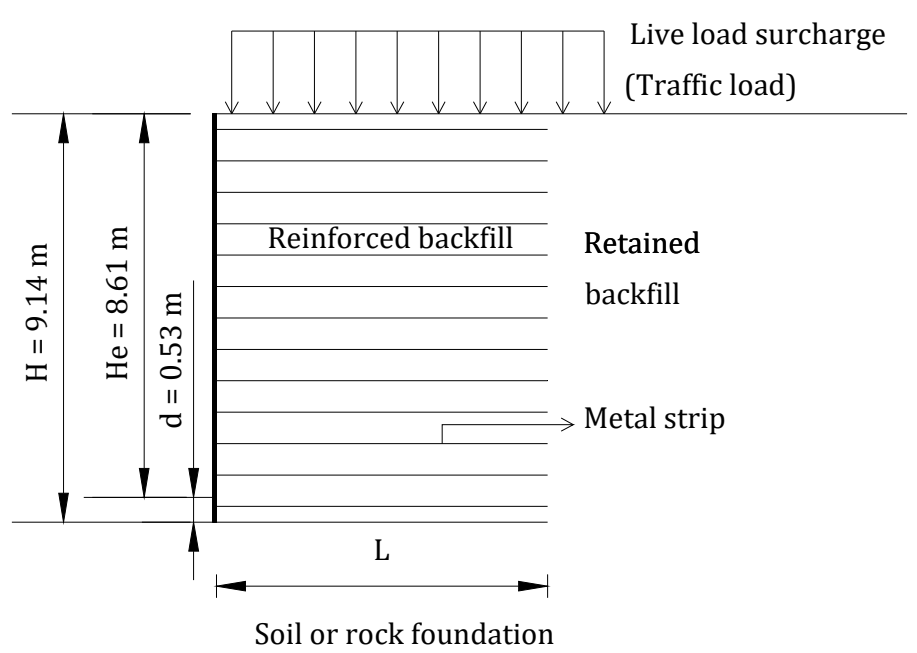

Figure 9 - MSE wall system of test example 2

Cost optimization of the MSE wall with level backfill and traffic load is carried out using the ADS algorithm and the numerical results for case-a are tabulated in Table 6. As shown in this table the algorithm locates a cost-effective design with a cost of \$ 323727.76 in case-a. In the obtained optimum design, RB-2 is adopted as the reinforced backfill soil type, and ST9, with a length of $\mathrm{L}=6.40 \mathrm{~m}$ and a vertical spacing of $\mathrm{S}_{v}=0.84 \mathrm{~m}$, is selected as the steel 
reinforcement for the investigated MSE wall. As shown in Table 6 the horizontal spacing of strips $\left(\mathrm{S}_{h}\right)$ may vary for different strip layers. Figure 10 shows the average cost optimization history of the ADS algorithm in case-a.

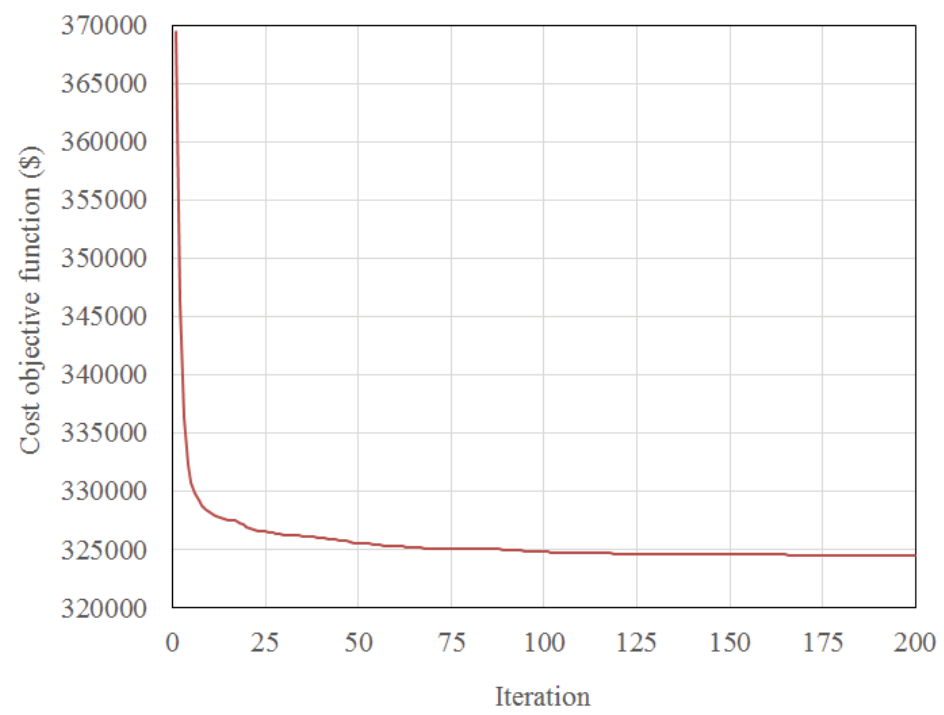

Figure 10 - Cost optimization history of test example 2-case (a)

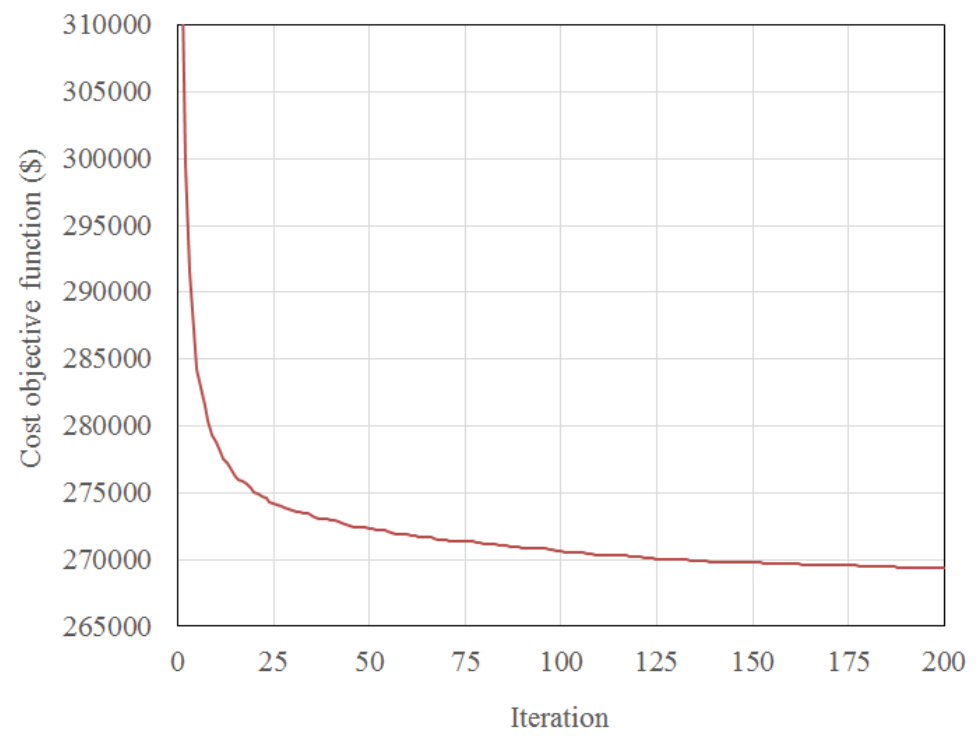

Figure 11 - Cost optimization history of test example 2-case (b) 


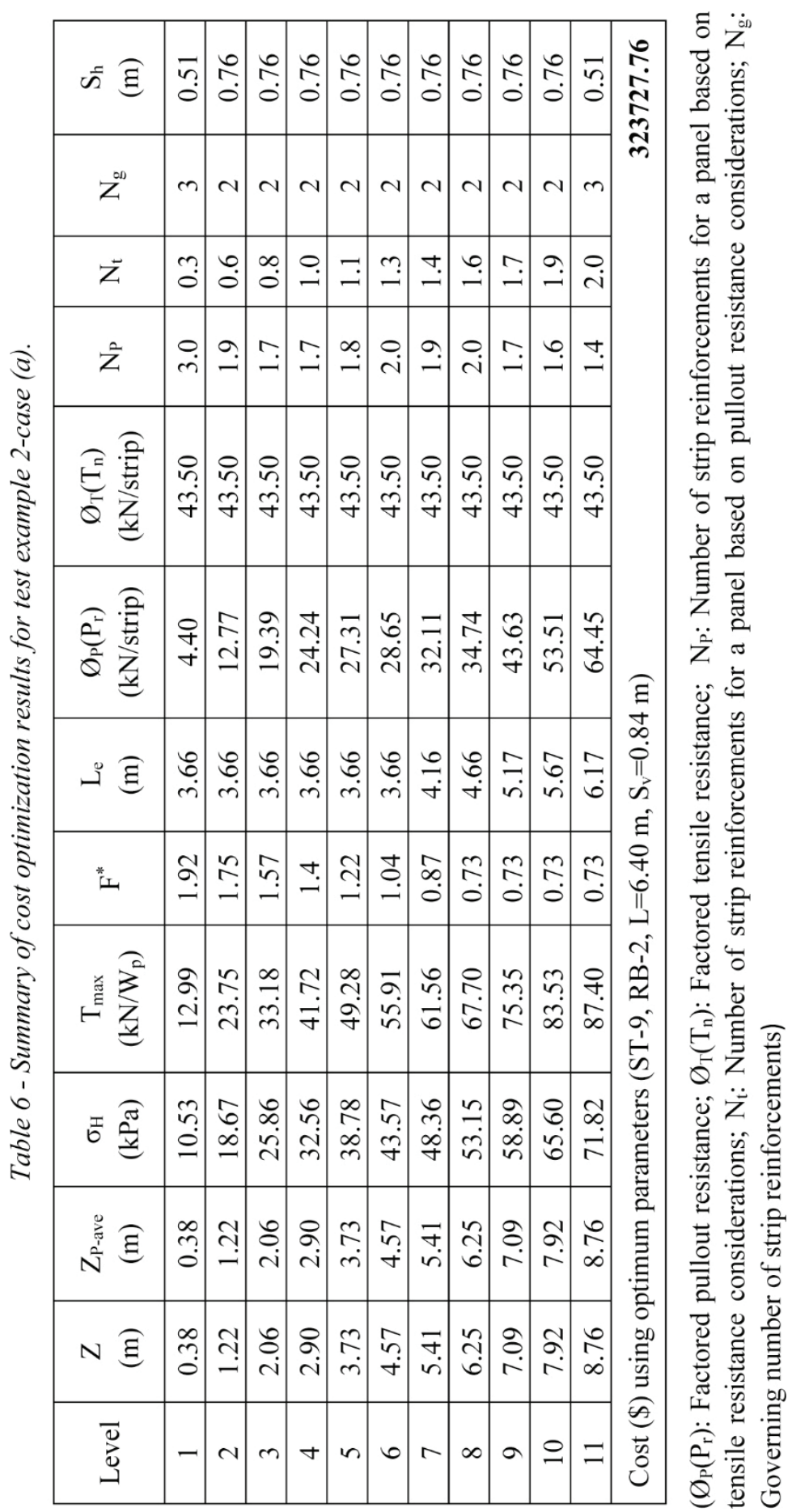




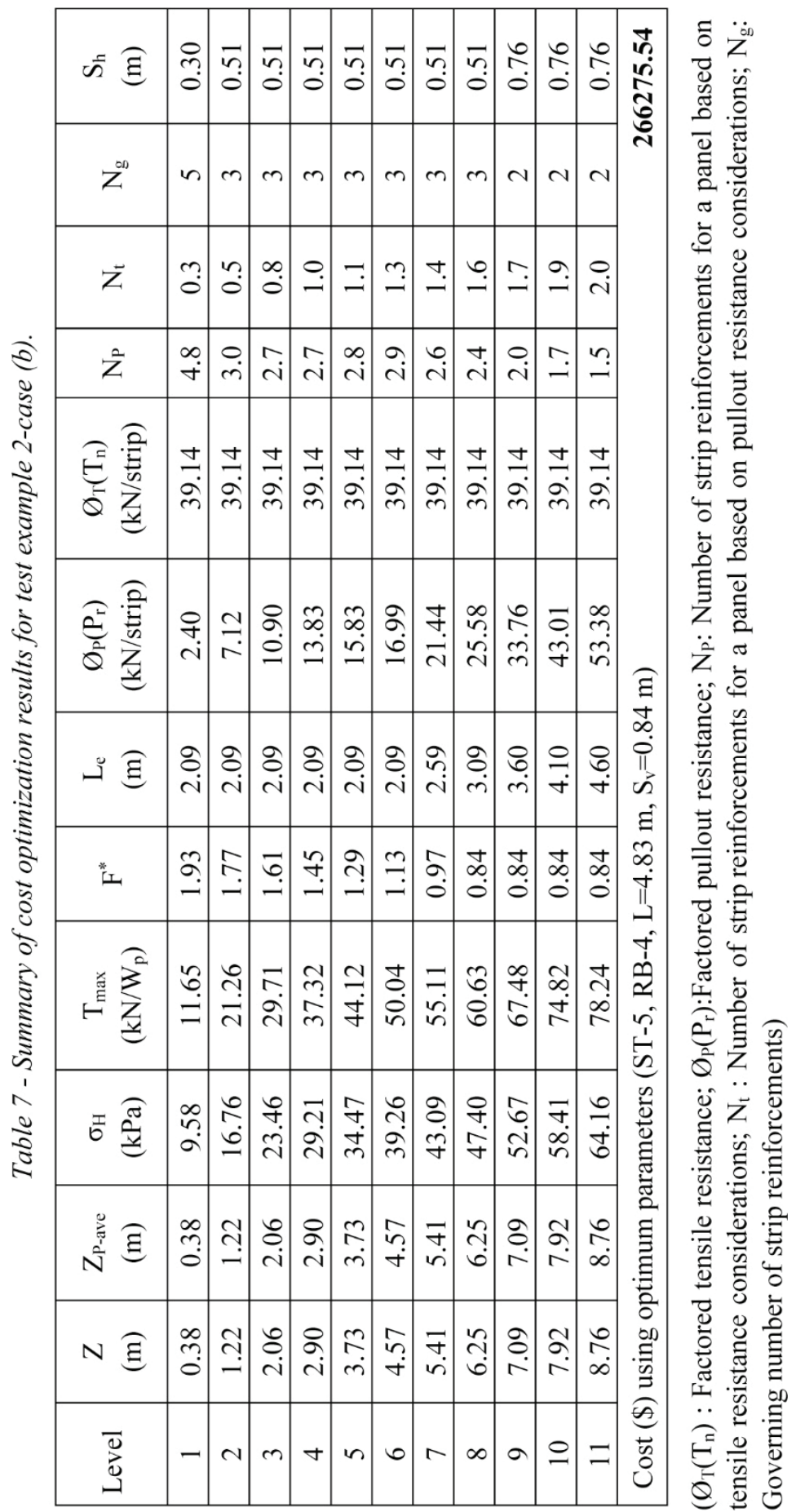


As mentioned before, in case-b the foundation is selected as rock. Accordingly, the internal friction angle and allowable bearing pressure of the rock foundation are taken as $45^{\circ}$ and 209 $10 \mathrm{MPa}$, respectively. In this case the lower bound on the length of steel strips is set to $0.4 \mathrm{H}$ where $H$ is the total height of the MSE wall [2].

The cost optimization results of case-b for the MSE wall with level backfill and traffic load are presented in Table 7. As can be seen from the table, in this case a minimum cost of $\$$ 266275.54 is obtained for the final design. For the optimum solution, the ADS finds RB-4 as the reinforced backfill soil type, and ST-5, with a length of $L=4.83 \mathrm{~m}$ and a vertical spacing of $\mathrm{S}_{v}=0.84 \mathrm{~m}$, as the steel reinforcement of the wall. The average cost optimization history of the ADS algorithm in case-b is plotted in Figure 11. It is worth mentioning that the comparison of final results obtained in two different cases shows a reduction of $18 \%$ in the cost of the investigated MSE wall in case-b compared to case-a.

\section{CONCLUSIONS}

In the present study, cost efficient design optimization of mechanically stabilized earth walls is performed using a recently proposed metaheuristic algorithm, namely adaptive dimensional search. For a minimum cost design, different types of steel reinforcement as well as reinforced backfill soil are considered as discrete solution variables. The performance of the adaptive dimensional search algorithm is evaluated through design examples of mechanically stabilized earth walls under realistic design criteria stipulated by standard design codes. The obtained numerical results indicate that the ADS algorithm can be efficiently employed for cost optimization of mechanically stabilized earth walls in real world applications. Furthermore, comparison of the final designs obtained in different test cases reveal that improving the foundation properties may be considered as an alternative way to further reduce the total cost of the mechanically stabilized earth walls in practical applications.

\section{References}

[1] Coduto, D.P., Foundation Design Principles and Practices, 2nd Edition, 2001.

[2] Berg R.R., Christopher B.R. and Samtani N.C. Design of Mechanically Stabilized Earth Walls and Reinforced Soil Slopes - Volume I, Department of Transportation FHWA, Washington, D.C., USA, 2009.

[3] Berg R.R., Christopher B.R. and Samtani N.C. Design of Mechanically Stabilized Earth Walls and Reinforced Soil Slopes - Volume II, Department of Transportation FHWA, Washington, D.C., USA, 2009.

[4] H. Ghiassian, K. Aladini, Optimum design of reinforced earth walls with metal strips; simulation-optimization approach, Asian Journal of Civil Engineering (Building and Housing), 10 (6): 641-655, 2009.

[5] P.K. Basudhar A. Vashistha K. Deb, A. Dey, Cost optimization of reinforced earth walls, Geotech. Geol. Eng., 26: 1-12, 2008. 
[6] Goldberg DE, Samtani MP. Engineering optimization via genetic algorithm. Proceeding of the Ninth Conference on Electronic Computation, ASCE, pp. 471-482, 1986.

[7] Kirkpatrick S, Gerlatt CD, Vecchi MP. Optimization by simulated annealing, Science, 220: 671-680, 1983.

[8] Kennedy J, Eberhart R. Particle swarm optimization. In: IEEE international conference on neural networks, IEEE Press, pp. 1942-1948, 1995.

[9] Colorni A, Dorigo M, Maniezzo V. Distributed optimization by ant colony. In: Proceedings of the first European conference on artificial life, USA, pp. 134-142, 1991.

[10] Dorigo M. Optimization, learning and natural algorithms, $\mathrm{PhD}$ thesis. Dipartimento di Elettronica e Informazione, Politecnico di Milano, Italy, 1992.

[11] Lee KS, Geem ZW. A new structural optimization method based on the harmony search algorithm, Comput. Struct., 82: 781-798, 2004.

[12] Yang X-S. Nature-inspired metaheuristic algorithms, Luniver Press, UK, 2008.

[13] Erbatur F, Al-Hussainy MM. Optimum design of frames, Comput. Struct. 45: 887-891, 1992.

[14] Tabak EI, Wright PM. Optimality criteria method for building frames, J. Struct. Div., 107: 1327-1342, 1981.

[15] Lamberti L, Pappalettere C. Metaheuristic design optimization of skeletal structures: a review, Computational Technology Reviews, pp. 1-32, 2011.

[16] Saka MP. Optimum design of steel frames using stochastic search techniques based in natural phenomena: a review, in: B.H.V. Topping (Ed.), Civil Engineering Computations: Tools and Techniques, Saxe-Coburg Publications, Stirlingshire, UK, pp. 105-147, 2007.

[17] O. Hasançebi, S. Kazemzadeh Azad, Adaptive dimensional search: A new metaheuristic algorithm for discrete truss sizing optimization, Comput. Struct. 154, 1$16,2005$.

[18] American Association of State Highway and Transportation Officials (AASHTO), LRFD Bridge Design Specifications, 5th Edition, 2010. 